\title{
Solar-optimum design principles for office buildings
}

\author{
Anatolijs Borodinecs ${ }^{1 *}$,Juris Sorokins ${ }^{1}$, Yulia Bykova $^{2}$, and Anna Nefedova $^{2}$ \\ ${ }^{1}$ Institute of Heat, Gas and Water Technology, Riga Technical University,Riga, Latvia, Kipsalas \\ street $6 \mathrm{~A}$ \\ ${ }^{2}$ Civil Engineering Institute, Peter the Great Saint-Petersburg Polytechnic University, St.Petersburg, \\ Russian Federation, Polytechnicheskaya, 29
}

\begin{abstract}
New concept of passive cooling of buildings is presented in this article.. In order to achieve that, it is planned to define three basic elements of the building concept - shape of building, sun movement and sustainability of the building. These parameters will serve as corner stone's also further in development of building concept. In addition not only passive cooling elements are considered during concept elaboration process but also passive building basic principles which include building location, window placement on facades, room alignment, building constructions and high comfort level. Dynamic simulation software was used in order to perform calculations, and to make conclusions on most optimal window/wall proportions and passive cooling potential. Paper presents study on multi apartment buildings renovation specifics in Latvia and its influence on total energy consumption. The necessary reconstruction goals are defined to reach European Regional Development Fund project "A New Concept for Sustainable and Nearly Zero-Energy Buildings" Nr. 1.1.1.1/16/A/007 main targets.
\end{abstract}

\section{Introduction}

Nowadays passive house concept is implemented in all energy efficient buildings. Passive House Institute designed standard for energy-efficient passive buildings. The buildings following Passive house principles should provide optimal indoor air parameters with very low energy consumption. Also it is very important to ensure visual comfort in buildings especially in office type buildings as the persons usually stay there during the sunny time of the day. In order to prevent room's visual discomfort level, several qualifying values are introduced. One of such values is daylight glare probability or DGP [1].

In is assumed that optimal IAQparameters include the following: temperature between +20 and +24 and $\mathrm{RH}$ between $40 \%$ and $60 \%$, as well as $\mathrm{CO}_{2}$ level below $1000 \mathrm{ppm}$ [2]. The U-value is taken 0.8 for windows and 0.1 for walls and roofs by the passive house concept, The exact U-values of the building envelopes will vary in each case depending on several factors like parameters of outside air during heating season, size and type of building, architecture and availability of energy resources. The optimal insulation thicknesses must

*Corresponding author: Anatolijs.borodinecs@,rtu.lv 
be calculated for each region to make the building consume very low amount of energy at the same time ensuring the feasibility. In fact one of the major influences to choose such low energy consuming buildings over standard ones would come in case if they would not only be environmentally friendly but also economically beneficial. Such economical estimation is challenging task but several existing methods have been provided. Such as big bang-big crunch method which can be successfully used for optimal green building design which would satisfy both the energy efficiency demands on one side and economy aspects on the other [3] or simpler life cycle analysis method [4].

Today in passive houses different energy efficient technologies such as sun energy, energy from internal heat sources, heat regeneration are used to reducing required heating capacity. To minimize energy consumption by mechanical heating and cooling the optimal windows size and orientation as well as dynamic shading should be introduced.

Windows in many cases are the most important element of the building envelope defining the look and characteristic of the building and play a significant role in building architectural design. From the technical point of view, windows simultaneously should ensure following functions:

- To minimize building heat losses in winter time;

- To reduce external heat gains in summer time;

- To insure possibilities for passive heating;

- To provide natural daylight;

- In some case (natural ventilation and/or night cooling) to provide air exchange.

As it can be seen from above mentioned description, windows have to provide selfexcluding functions. So, the window and shadings properties should be chosen taking into account the type of ventilation, requirements to thermal comfort and energy consumption, orientation of building facades, human behaviors and etc. Such complex simulations must be done through help of simulation software. The whole building energy simulation programs must be employed in the first steps of the design process to help architectures and engineers to take the best decision, and to choose which alternatives design are more energy efficient and cost effective [5].

In order to reduce overheating, appropriate shading should be used especially on the non-North facing sides. External shading devices are alternative and more efficient way compared with indoor shading. Natural shading elements such as trees can also be used efficiently. The choice of the type and size of shading devices depends on solar geometry. Main function of external building envelope is to create physical barrier between outer and inner environment. It serves as external shell that helps to keep necessary indoor air parameters (together with air conditioning systems) and to promote indoors micro climate control.

Climate conditions are mostly described by annual air temperature. Data regarding outside temperature can be obtained from various sources. Depending from desired precision of calculation, select average data about different time intervals - average hourly, daily, monthly temperature for all year of the calculations. The influence of outdoor air parameters on energy consumption by HVAC systems is shown in Fig. 1. 


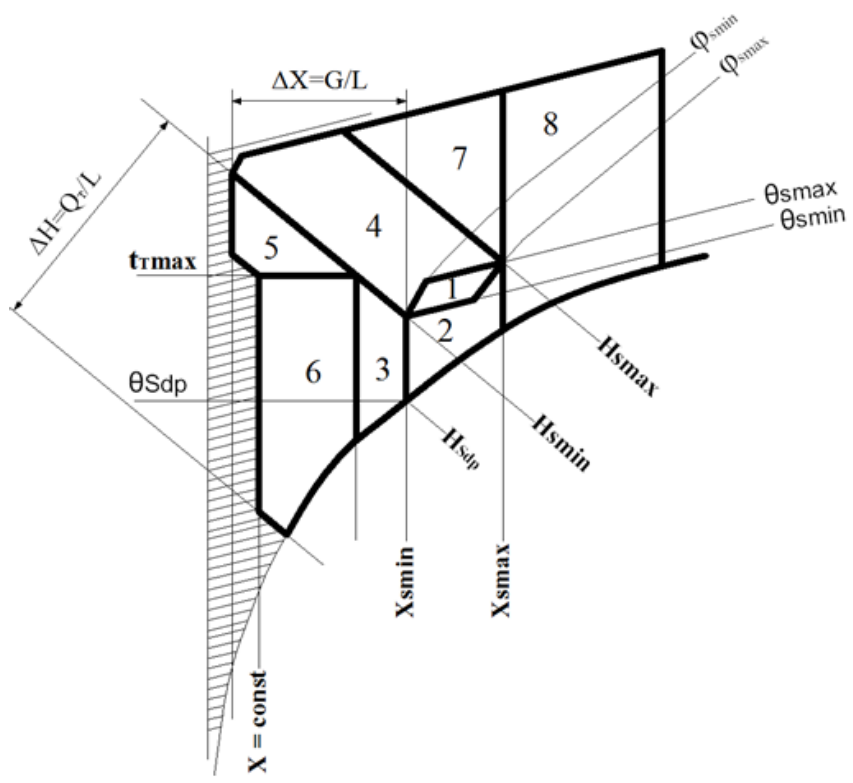

Fig. 1.The indoor air comfort zone and regulation regimes on $\mathrm{H}-\mathrm{x}$ diagram $(\mathrm{H}-$ enthalpy, $\mathrm{kJ} / \mathrm{kg} ; \mathrm{x}-$ moisture content, $\mathrm{g} / \mathrm{kg} ; \theta$ - temperature, ${ }^{\circ} \mathrm{C} ; \varphi$ - relative humidity; QT - heat source capacity, $\mathrm{kW} ; \mathrm{G}$ - humidifier capacity, g/s; L - air quantity, $\mathrm{kg} / \mathrm{s}$.цитатасссылкойнастатью

For improvement of energy efficiency and in order to achieve zero net energy building requirements, a strong option would be utilization of solar energy both for generating solar thermal and electrical power. However, the actual obtained energy of solar collectors depends on their orientation, shading from trees as well as efficiency of the system. The data on how the efficiency changes depending on the inclination angle and orientation is shown in Tables 1 and 2 [6].

Table 1. System efficiency dependency on inclination angle of solar collector

\begin{tabular}{|c|c|c|c|c|c|c|c|}
\hline Inclination angle to the horizontal & $0^{\circ}$ & $15^{\circ}$ & $30^{\circ}$ & $45^{\circ}$ & $60^{\circ}$ & $75^{\circ}$ & $90^{\circ}$ \\
\hline Heating efficiency & 0,71 & 0,85 & 0,94 & 1,00 & 1,00 & 0,98 & 0,88 \\
\hline Heating and DHW efficiency & 0,59 & 0,74 & 0,89 & 1,00 & 1,06 & 1,06 & 0,97 \\
\hline
\end{tabular}

Table 2.System efficiency dependency on orientation of solar collector

\begin{tabular}{|c|c|c|c|c|c|c|c|}
\hline Deviation from the south & $0^{\circ}$ & $15^{\circ}$ & $30^{\circ}$ & $45^{\circ}$ & $60^{\circ}$ & $75^{\circ}$ & $90^{\circ}$ \\
\hline Heating efficiency & 1,00 & 0,99 & 0,97 & 0,93 & 0,88 & 0,81 & 0,73 \\
\hline Heating and DHW efficiency & 1,00 & 0,98 & 0,95 & 0,89 & 0,81 & 0,73 & 0,64 \\
\hline
\end{tabular}

\section{Impact of solar radiation}

When solar radiation interacts with some surface (for example, glass, shading fabric or metal), it divides into three parts: [7]

1) translucency $\tau$, that indicate part of translucent flow from total falling light flow; 
2) reflection $\rho$, that indicate part of reflected flow from the total falling light flow;

3) absorbing capacity $\alpha$.

The sum of all these factors always equals $100 \%$, or $\tau+\rho+\alpha=100 \%$

Specific radiation falling to the surface $\mathrm{E}$, transluced radiation equals with $\tau \cdot \mathrm{E}$, absorbed radiation equals with $\alpha \cdot E$ and reflected radiation equals with $\rho \cdot E$.

Translucency, reflection and absorbing are characteristic values which are characteristic to specific material depending from their physical properties. Also these characteristic values depend from the wave length of solar radiation. It is possible to measure these properties at specific wave length and obtained values are called material spectral data.

\section{Office building concept}

The aim of the research is to develop building concept for three story office building using architectural elements of passive cooling. In order to achieve that it is planned to define three basic elements of the building concept - shape of building, sun movement and sustainability of the building. These parameters will serve as corner stones also further in development of building concept. In addition not only passive cooling elements are considered during concept elaboration process but also passive building basic principles which include building location, window placement on facades, room alignment, building constructions and high comfort level [8-15].

Dynamic simulation software IESVE is used in order to perform required calculations, and after analyzing obtained results to make conclusions and relevant improvements, in that way providing most beneficial result. In specific the designed atrium is used to provide natural ventilation thus reducing energy consumption of the building that would be used for ventilation facilities and running of cold air pre-heater. Operation principle of natural ventilation is shown in Fig.2.

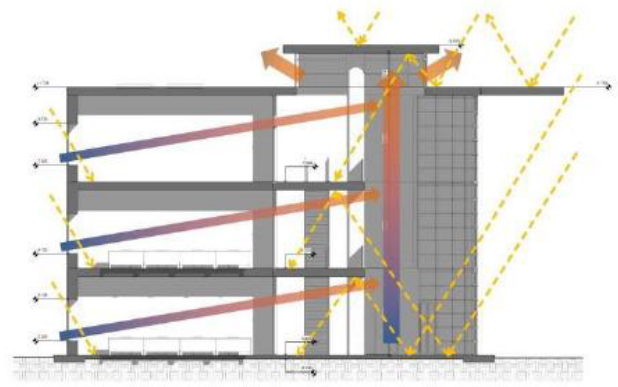

Summer

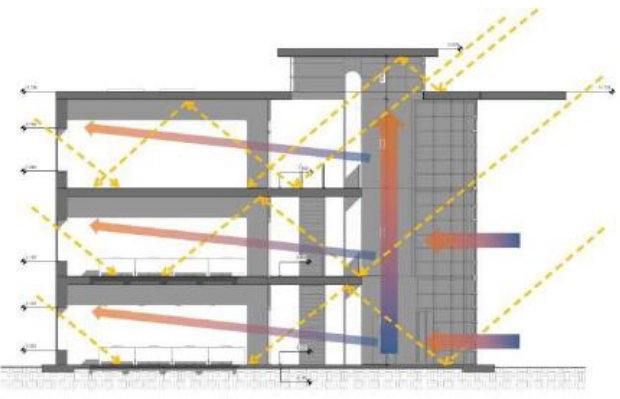

Winter

Fig.2.Chimney effect in designed buildings atrium

In summer chimney effect in atrium facilitate discharge of excess hot air from the building. In winter sun in the atrium pre-heats the cold outside air and provides additional insulation. Ellipse-type shape of the building (Figure 3) is adapted to replicate movement of the sun, therefore using the most of sunlight and energy, at the same time building fits well with all types of landscape. In order to provide comfortable working conditions to office employees, taking into account sun movement path in the sky during daylight, main office rooms are located along the north facade of the window, that way avoiding direct solar rays and risk of glare. 


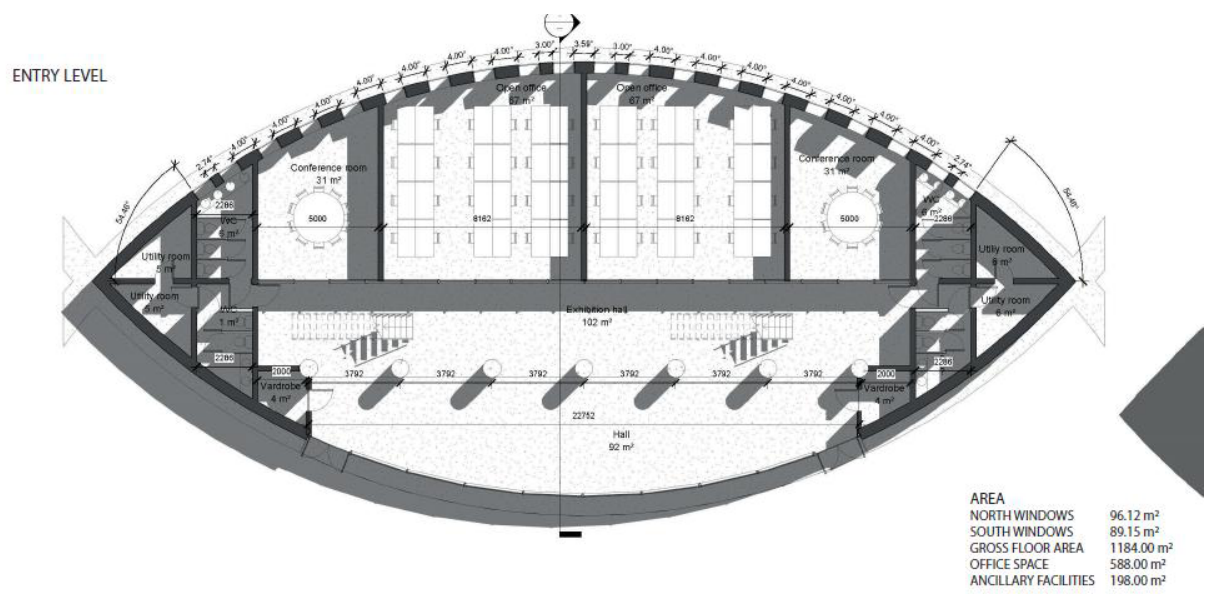

Fig. 3. $1^{\text {st }}$ floor plan of designed building

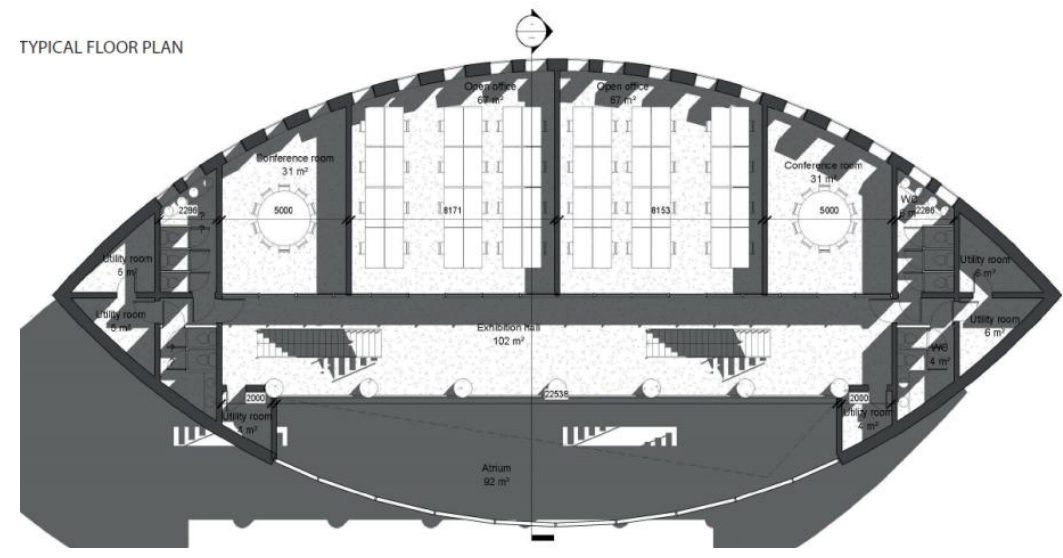

Fig. 4. Typical floor plan of designed building

In developed concept of office building, in accordance to performed computer simulations on IESVE software, for office space areas the average weighted daylight factor is optimal - in the range between 2 and $5(\%)$ as it is seen in Fig.5. 

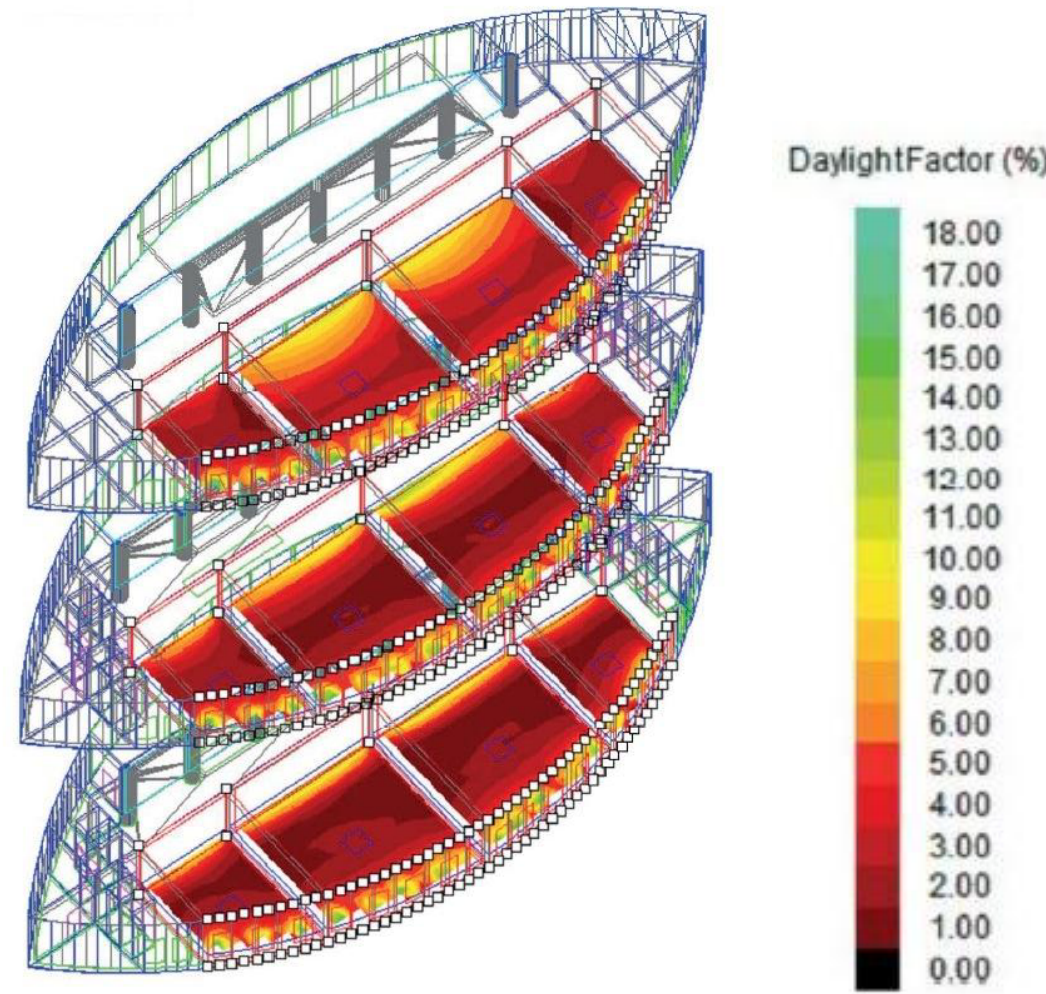

Fig.5. Office space areas - average weighted daylight factor distribution

ES-SO and REHVA manual [5] compiles scientific research summary which shows impact of daylight use to the factors related to productivity of staff and students:

- Carnegie-Mellon University discovered that by increasing use of daylight that does not cause glare and by providing daylight lighting control, on average $3.75 \%$ of productivity increase was obtained[5];

- On average complains about serious illnesses decrease by $20 \%$ and $25 \%$ to residents that are located close to outer window in comparison to those who work deep indoors without access to daylight[5];

- Access to window and daylight reduced not showing up at work by $15 \%$ [8];

- Direct sun access to the classrooms, especially through non shadowed East or South windows is linked to negative performance of the students [5].

Direct radiation distribution on the facades of concept building during the year (in hours) is shown in Fig.6.

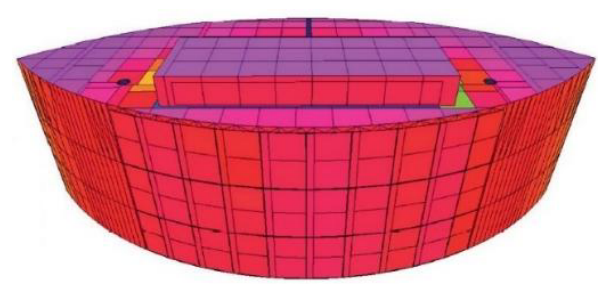

South facade

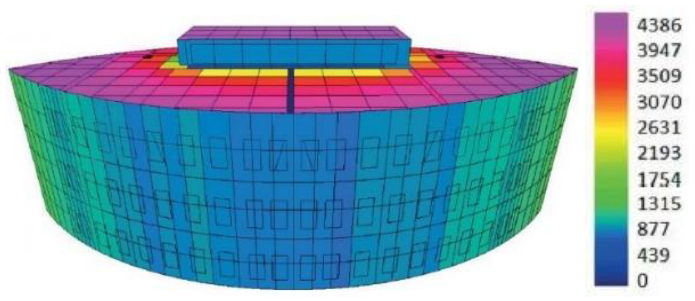

North facade

Fig.6.Direct radiation distribution on South and North facade 


\section{Conclusions}

Ellipse-type shape of the building is adapted to replicate movement of the sun, therefore using the most of sunlight and energy, at the same time building fits well with all types of landscape. Big, wide windows on the south facade of the building make the building light and lightweight. At the same time in order to prevent direct solar radiation and reduce overheating in the summer, an overhang is applied. Whereas on north facade of the building narrow and long windows are used, to satisfy the need for natural daylight indoors at working places at the same time to keep the energy consumption of the building as low as possible. The main office rooms are located along the north façade, that way avoiding direct solar rays and risk of glare, in order to provide comfortable working conditions for office employees. Transparent wall separating office spaces from atrium provides possibility to use diffused sunlight, as well as makes interior of the office building modern. Use of such transparent wall provides optimal office room weighted daylight factor - in boundaries between 2 and $5(\%)$.

Ellipse-type shape of the building provides not only maximum sunlight and energy use also provides optimal ratio between building's bordering structure surface area and volume of the building. It is understandable that - the smaller the area of outer walls, the smaller heat loses and construction and operation costs if calculated according to $1 \mathrm{~m}^{2}$ of usable area. Use of atrium facilitates building's sustainability that provides natural ventilation. In summer due to chimney effect influence, atrium promotes discharge of heated air but in winter sun pre-heats cold outside air and provides additional insulation. At the same time simple shape of the building provide reduced thermal bridge number and consequently smaller heat loses.

\section{Acknowledgements}

This study was supported and financed by European Regional Development Fund project "A New Concept for Sustainable and Nearly Zero-Energy

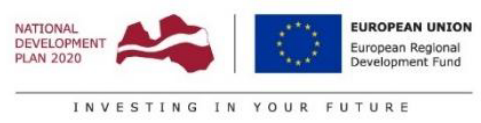
Buildings"Nr.1.1.1.1/16/A/007.

\section{References}

1. C. A. Anker Hviid, T. Rammer, S. Svendsen, Solar Energy, 82, pp. 787-798(2008)

2. A. Borodinecs, A. Kreslins, E. Dzelzitis, A. Krumins, Proceedings of the 6th Int. Conf. on Indoor Air Quality, 2007)

3. A. Milajić, D. Beljaković, N. Davidović, N. Vatin, V. Murgul, Procedia Engineering, 117 (1), 916-923 (2015)

A. N. Gorshkov, N.Vatin, D. Nemova, A. Shabaldin, L. Melnikova, P. Kirill, Procedia Engineering, 117 (1), pp. 1085-1094 (2015)

4. Z. Abdellah, E. Dzelzītis, A. Borodinecs, Building Tomorrow Today: XI International HVAC+R Technology Symposium, 542-546 (2014)

5. P. Shipkovs, G. Kashkarova, K. Lebedeva, J. Shipkovs, Proceedings of the Solar World Congress 2005: Bringing Water to the World, 2.2, 1378-1383 (2005)

6. European Solar Shading Organization, Solar shading for low energy buildings, (Meise, Belgium 2011)

7. S. Petersen, Simulation-based support for integrated design of new low-energy office buildings, PhD Thesis, DTU-Tryk, (2012) 
8. K. Carrier, S. Ubbelohde, Proc. of the Solar World Congress 2005 Including Proc. of 34th ASES Annual Conf. \& Proceedings of 30th National Passive Solar Conf., 539 - 545 (2005)

9. CIBSE Lighting Guide 10: Daylighting and window design, (CIBSE, United Kingdom, 1999)

10. Indoor environmental input parameters for design and assessment of energy performance of buildings addressing indoor air quality, thermal environment, lighting and acoustics. LVS EN 15251:2007.

11. G. Radović, V. Murgul, M. Cvetkovska, E. Aronova, N. Vatin, Journal of Applied Engineering Science, 12 (4), 277 - 284 (2014)

12. V. Murgul, N. Vatin, I. Zayats, Procedia Engineering, 117, 824-829 (2015)

13. E. Aronova, N. Vatin, V. Murgul, Procedia Engineering, 117, 771-779 (2015)

14. S. Paunović-Žarić, V. Radulović, E. Alihodžić-Jašarović, V. Murgul. Journal of Applied Engineering Science, 14(1), 140 - 147 (2016)

15. Norbert Harmathy, Vera Murgul, Procedia Engineering, 165, 1845-1852 (2016) 